\title{
Using the activity method to enhance students' performance in energy transformation
}

\author{
Adu-Gyamfi, Kenneth $\bowtie$ \\ Mampong Technical College of Education, Ghana (dondonsinco@yahoo.com)

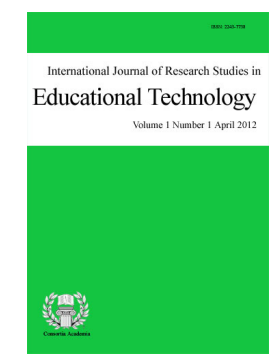

ISSN: $2243-7738$ Online ISSN: 2243-7746

OPEN ACCESS

\section{Abstract}

The study sought to investigate the effects of Activity Method (AM) on 53 Junior High School students' performance in energy transformation at the Sekyere South District of the Ashanti Region of Ghana. The study investigated the comparative efficiency of the AM and the traditional lecture method in energy transformation in Integrated Science. A pretest-posttest action research design was used as the main design for the study. The students from the experimental group were taught with the AM whereas the students from the control group were taught with the traditional lecture method. Means, standard deviations, and Mann-Whitney U tests were used to analyze the scores from the pretest and posttest scores of the students. The findings from the study show that the students from the experimental group performed creditably well than the students from the control in the posttest. Hence, the AM enhanced the performance of the students in energy transformation.

Keywords: activity method; action research; students' performance; energy transformation 


\section{Using the activity method to enhance students' performance in energy transformation}

\section{Introduction}

Various methods of teaching science have been introduced at the Basic School level (that is, the Primary and Junior High School [JHS] levels) in Ghana. The Activity Method (AM) is one of such methods considered for the teaching and learning of science at the JHS level in Ghana. The AM of teaching places the student at the centre of the teaching and learning process where the student is made to interact with teaching and learning materials (TLMs) to discover scientific concepts, facts, or principles with or without any teacher support. The materials used by the students in an AM lessons are either provided by the teacher or the students (Ministry of Education, Youth, and Sports [MOEYS], 2006). In an activity lesson, the teacher introduces the topic and distributes the TLMs as well as the instructions for the activity for the students to carry out the activity on their own to discover the new scientific concept or idea. The teacher then acts as a co-learner showing interest in the students' activity (Khan \& Iqbal, 2011; MOEYS, 2006).

The AM due to its nature has been given several names one of which is Inquiry Science. McBride, Bhatti, Hannan, and Feinberg (2004) found out that during the training of teachers to teach Science (Physics) by inquiry, the instructors for the program acted as co-learners by monitoring the teachers involved in the activities and where necessary gave direction to them. This is a characteristic feature of an AM of science teaching where the students are placed at the center of the teaching and learning process to form scientific concepts with little or no interference of the science teacher.

The AM is the preferred choice of science teaching and learning at the JHS level because it takes advantage of the Piaget's concrete operational developmental stage of knowledge construction (MOEYS, 2006). Students at younger ages learn very well when real (tangible) objects which are accessible to their senses are used. The use of concrete materials equips younger students with the skill of manipulation of symbols, logical reasoning, and generalization (American Association of the Advancement of Science [AAAS], 1990). Piaget demonstrated that students at the concrete operational stage by nature show peculiar behaviors when at play or using materials within their environment and those students differ in demonstrating such behaviors due to their genetic and environmental factors. Hence, when AM is used in teaching science, individual students are allowed to form concepts at their own pace. This helps students to easily remember the concept learnt.

From AAAS (1990), students existing ideas prior to the teaching and learning of any new knowledge lay the foundation for the construction of the new knowledge. The students learn the new knowledge by creating a linkage between the new and the existing knowledge or restructuring the new and the existing knowledge. The AM is said to make use of the linkage and reconstruction of the new and existing knowledge as expressed by the AAAS (1990) and hence, according to MOEYS (2006), one of the reasons for the use of AM at the JHS level is that it takes advantage of the students' familiarity with the environment and the play materials. Then it could be said that the observation made by Clark (2003) was not out of place. Clark (2003) observed that in a primary school science lesson, the activity the students were engaged in was based on materials which were simple and familiar to the students.

The AM of science teaching gives students sufficient time to carry out the activity in discovering the new knowledge and this is appreciated by the AAAS (1990). Hence, AAAS (1990) asserted that the teaching and learning of science should be carried out in such a way that students will have enough time to explore, observe, collect, sort, test ideas, measure, record, draw, interview, survey, compute, and to skillfully handle scientific implements. This enhances students' retention of scientific concepts, and hence, the students' performance on such concepts. 
Using the activity method to enhance students' performance in energy transformation

According to Khan and Iqbal (2011), an inquiry-based science lesson is a student-centered method of teaching which provides students with the opportunity to ask questions and follow instructions to arrive at new knowledge, and provide students in a science class the opportunity to think and reason critically (Pratt \& Hackett, 1998). Khan and Iqbal (2011) revealed that there was a statistical significant difference in the mean performance of the students who were taught some scientific skills in Biology with the inquiry laboratory teaching method and students who were taught the same scientific skills with the traditional teaching method in the posttest. The findings of Ergul et al. (2011) show that the mean score of students who were taught the science process skills through the inquiry-based approached was higher than those students who were in the control group. This shows that the acquisition and performance of students in the science process skills were enhanced through inquiry-based science teaching which is an activity-based. McBride et al. (2004) concluded their work by saying that the use of an activity-based lesson such as teaching Physics by inquiry has helped improved the performance of students in Physics thereby gaining admission to the universities.

From Ergul et al. (2011), it was found out that combination of hands-on activities and inquiry science teaching help improve the attitude of students towards the study of science. This was based on the fact the attitude of the students in the experimental group was said to have improved with respect to that of their counterparts in the control group in the study conducted by Ergul et al (2011). In this current study an attempt was made to use locally available materials which are familiar to students instead of the conventional science equipment and materials to enhance the students' performance in a scientific concept.

In my teaching practice supervision of pre-service teachers, for the 2011/2012 academic year, from Mampong Technical College of Education in some towns in the Sekyere South District of Ashanti Region, I observed that the students of the JHS 2 class have a difficult in answering questions on energy transformation in some of the schools. It was therefore not out place to enhance the performance of students in energy transformation using the AM.

\subsection{Purpose of the Study}

The purpose of the study was therefore to use the AM to enhance students' performance in energy transformation. This was achieved by preparing an activity-based lesson and TLMs from locally available materials to teach students from two schools from two towns in the Sekyere South District. This is because students from the two schools were observed to have shown much difficulty in answering some questions on energy transformation than the students from the other schools. Whereas the students from JHS 2 class in one of the schools, A were been taught the concept of energy transformation with AM, students from JHS 2 class of the other school, B of the Sekyere South District were being taught with the traditional lecture method. The study was guided through by the research question: to what extent can the activity method help to improve the performance of students in energy transformation.

\section{Methodology}

The study used two groups of students from two schools in different towns. The performance of the students in pretest was compared to that of their posttest on energy transformation. Thus, the study investigated the students' knowledge in energy transformation by comparing test responses of the students before and after instruction. The extent of the difference between the performances of the students from the two schools was investigated further by comparing individual performances. The conclusion of the study was drawn based on the effects of the used AM on students' performance in energy transformation. As such, when the research question is answered, Basic School science teachers would appreciate the effects of AM on the teaching and learning of science and researchers in the area of science education could further try the AM in others parts of the world to ascertain its efficacy on students' learning at the Basic School. 


\subsection{Research Design}

The study used quantitative methods to investigate the effects of AM on the students' performance in energy transformation. With the help of action research design, which can be used in any situation where problems involving students seek solution, quantitative data on students' performance in energy transformation were obtained. This is because action research can be used in the variety of areas such as teaching methods (Cohen, Manion, \& Morrison, 2005), and in this study the used of AM and traditional lecture method on the concept of energy transformation. According to Kemmis and Taggart (as cited in Cohen et al., 2005), action research is more systematic and collaborative in data collection and not the routine way teachers prepared for their classroom practices. It is built on the concept of problem-posing instead of problem-solving, and hence could help to improve students' performance in scientific concepts and principles such as energy transformation. Thus, the activities used for the investigation of students' performance in energy transformation were structured in such a way that they were systematic and problem-posing which had the potential of improving the performance of students in energy transformation.

\subsection{Sample}

Two schools, A and B from two towns in the Sekyere South District of Ashanti Region of Ghana were involved in the study. This is because the problem under study was identified with the students from these towns. The two communities in Sekyere South District are predominantly farming communities with most of the inhabitants belonging to the Asante Ethnic Group who speak 'Asante Twi' as their first language and English Language as the second language. However, the medium of instruction for all categories of students is the English Language. The two communities from which the two schools were selected were of the low socio-economic status, where in Ghana it is usually less-endowed with equipment and facilities for teaching and learning, especially science. The time available for teaching and learning of science in each school was 140 minutes, which was divided into double periods of 70 minutes each. The double periods were also allocated on separate days on the schools' time-table.

A purposive sampling technique was used in selecting the students who participated in the study (Cohen et al., 2005). It was purposive because the students involved in the study were selected from the two schools where the problem was identified. And because the students from the two schools further helped to compare the effects of AM instruction on students' performance in energy transformation within the four weeks of the study. An intact class (JHS 2) each from schools A and B in the Sekyere South District were involved in the study. This is partly because all members of both classes were concerned and each JHS 2 student was a special individual which meant a variety of interest and variety of level of understanding. The students from school A were placed in the experimental group and the students from school B were placed in the control group. The groupings were based on the mean scores of the students from the two schools in the pretest. There were 53 JHS 2 students consisting of 23 and 30 students respectively from schools A and B involved in the study. From school A, 52.2\% of the students were female students and from B, $50.0 \%$ of the students involved were female students.

\subsection{Research Instrument}

The main research instrument used for the study was achievement test, which was constructed by me. A five-item test was used before the intervention (as a pretest) to determine the level of performance of students involved in the study on energy transformation in the first week of the study. Short-answer type test was used in the pretest which lasted for 30 minutes. The test items were: Identify the energy changes that occurred in the following situation;

$>\quad$ When Michael peddled his bicycle from his house to church for evening service yesterday night.

$>\quad$ A mango fruit falling from a mango tree. 
$>$ Your father switching on the television set in your house yesterday night.

$>$ Kwame playing the strings of the guitar at church service.

$>$ Quickly rub your two palms together for about two minutes, and quickly touch your face with your palms.

The same short-answer test items but with different arrangement and changes in the use of some words in the items was used after the intervention (as a posttest) at the fourth week of the study to find out whether the performance of the students in energy transformation has improved. The purpose of the new arrangements of the test items for the posttest was to ensure that the test items look new. The new arrangements were: Identify the energy changes that will occur in the following situations;

$>$ Awuah playing the strings of the guitar at the school open-day.

$>$ Quickly rub your two palms together for about two minutes, and quickly touch your face with your palms.

$>$ An orange fruit falling from an orange tree.

$>$ When Agyei peddled his bicycle from his house to school today.

$>$ Your mother switching on the television set in your house yesterday night.

The posttest also lasted for 30 minutes. Hence, the difficulty indices of the pretest and posttest items could be said to be the same. This is because the concepts being developed by the test items in the posttest were the same as those of the pretest. The achievement test was pilot-tested with an intact class of 21 JHS 2 students from a school in the Sekyere Central District of the Ashanti Region of Ghana, which was of similar characteristics as those schools used for the main study (Cohen et al., 2005; Pallant, 2005). The Cronbach's alpha coefficient reliability for the achievement test was calculated as 0.7. The purpose of calculating Cronbach's alpha coefficient reliability was based on the fact that the test items were not scored right or wrong but each correct stage of the energy transformation deduced by the students attracted a score of 1 mark.

\subsection{Data Collection Procedure}

Permission was sought from the Head teachers of schools A and B for the study to be conducted in their respective schools. The Head teachers and the members of staff were briefed on the purpose of the study and the number of weeks the study would cover. A briefing section was also organized for the students. The purpose was to ensure that the minds of the students were well prepared towards the study. As the design for the study was action research, the data collection procedure was structured as a three-stage one. The stages were pre-intervention, intervention, and post-intervention.

\subsection{Pre-Intervention Stage}

I observed that the students of the JHS 2 class of the two schools in the Sekyere South District have difficulty in responding to questions on the concept of energy transformation. To ascertain the extent of students' difficulty in energy transformation, the pretest was administered in the first week of the study in the two schools. The students' responses on the pretest were scored immediately after its administration. The five test items were scored out of 20 marks for the two classes from the two schools. The purposes were to select and group the students into the control and experimental groups.

After scoring the pretest, the mean scores of the two classes were calculated. The mean scores for the two classes were statistically significantly not different. The mean scores helped to conveniently place the two classes respectively from schools A and B into experimental and control groups. The class from the school with 
Adu-Gyamfi, K.

the higher mean was placed in the control group and the class from the school with the lower mean score was placed in the experimental group. However, the performance of the students in the pretest further showed that the students have difficulty in energy transformation. This prompted the plan to use the AM of teaching and learning to address the students' difficulty in energy transformation.

\subsection{Intervention Stage}

The AM of teaching and learning of science was used to address the low performance of students in energy transformation. At the first stage of the intervention, I prepared a 70 minute lesson plan to teach the concept; forms of energy in both schools in the second week of the study. This is because according to Herrmann-Abell and DeBoer (as cited in Herrmann \& DeBoer, 2011), students' difficulties in energy transformation is as a result of students' lack of knowledge in the forms of energy. Thereafter, the students in the experimental were put into six groups of four members each with the last group consisting of three members whereas I taught the students in the control group as a unit in the third week of the study using the lecture method. The students from the experimental and control groups were taught at different instances with respect to the time tables of the two schools.

For each of the 70 minutes activity lessons with the students from the experimental group, there were two main activities for which each group performed in turn. Thus, in the first activity lesson, Activities I and II were used and Activities III and IV were used for the second activity lesson. The activities were structured as:

I. Place one end of the nail on the steel block.

Hammer the end of the nail a few times.

Touch the hammered end of the nail briefly with your fingers.

What do you feel?

Discuss the energy changes that occurred among the group members.

Record your conclusion.

II. Dip a piece of cloth in the kerosene.

Light the cloth and let it burn for some time.

What do you observe?

Discuss the energy changes that occurred among the group members.

Record your conclusion.

III: Hold one end of the metal wire with a tong.

Then, position the other end of the metal wire in a strong flame from the coal pot.

Heat it until it burns with white hot.

Quickly remove the heated metal wire to a darkened environment.

What do you observe?

Discuss the energy changes that occurred among the group members.

Record your conclusion.

IV: Connect the long piece of the resistance wire to two dry cells joined together to a battery as in Figure 1:

Close the key.

Touch the wire. What do you feel?

Now, reduce the length of the wire and repeat the process.

Continue reducing the length of the wire until it glows.

NB: Do not touch the wire when it glows. 


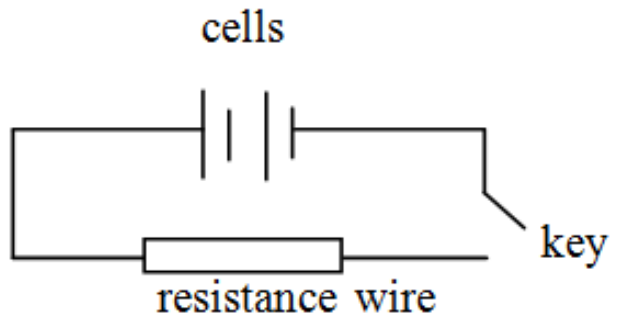

Figure 1. A Circuit Diagram involving Two Dry Cells, Resistance Wire, and a Key

What do you observe?

Discuss the energy changes that occurred among the group members.

Record your conclusion

Before the activity lesson, I tried out the activities so that I can anticipate problems that may evolve during the actual lesson and plan on how to combat them if they arise during the lesson. The students were asked to read around the topic energy transformation and were also involved in the collection of some of the materials to be used during the lesson.

During the first activity lesson, I introduced the lesson by revising with the students the previous lesson on forms of energy with questions. The students responded to the teacher-made questions very well which showed that the previous lesson was a success. The TLMs for each activity (such as nails, steel blocks, hammers, metal wire, coal pots, improvised tongs, dry cells, keys, resistance wire, pieces of cloth, and kerosene) were given to the students in groups. Instructions were given to each group on how to perform the activities. The students were asked to interact with the materials so that they can find answers to their questions. The students were also allowed to communicate among their group members and record their observations and findings. I also asked questions as I moved from one group to another and gave praises to students when need arose. In another lesson in the third week of the study, the groups were assigned the other two activities (that is Activities III and IV) to perform.

After each lesson, I led a general discussion with the students to come out with the energy changes from one form to another in each activity. The forms of energy involved in the activities performed during the study were emphasized to the students.

\subsection{Post-Intervention Stage}

The posttest was conducted to find out if the students have overcome their difficulties in energy transformation after the intervention has been implemented. The posttest was conducted in the fourth week of the study. The same test used in the pretest was used but with different arrangement and some changes with respect to the used of some words which could not affect the energy changes the test items were assessing as in the case of the pretest.

\subsection{Analysis}

The data collected to answer the research question was analyzed using means, standard deviations, and Mann-Whitney U test. The means and standard deviations were used to bring out the differences between the students' performance in energy transformation in the pretest and the posttest. To test whether there was 
Adu-Gyamfi, K.

statistical significant difference between the performance of the students from the experimental and control groups in energy transformation, the Mann-Whitney $U$ test analysis was used because, in the first place, intact classes were involved in the study. Also, when the distribution of the scores from the pretest was tested using the Kolmogorov-Smirnov test, the value, .000 was calculated for both the control and the experimental groups as the significance level. This significance level of .000 of distribution was observed to have violated the normality test of the distribution of scores that call for the use of independent-samples t-test analysis to test the extent of the difference in the performance of the students from both the control and the experimental groups. This is because the calculated value of .000 was lower than the significant value of 0.05 , and for independent-samples t-test to be used to test an independent variable of two levels against a continuous dependent variable, the calculated significance level must be larger than 0.05. Hence, the alternative non-parametric test to that of the independent-samples t-test was selected as the Mann-Whitney $U$ test analysis (Pallant, 2005). The Mann-Whitney U test analysis was therefore used to show the extent of difference between the performance of the students from the experimental and the control groups in the test. The means, standard deviations, and the Mann-Whitney $U$ test analysis were conducted through the use of SPSS.

\section{Results}

The research question sought to find out the extent to which the AM can be used to help improve students' performance in energy transformation. This question was answered by first forming the control and experimental groups who responded to the pretest items on energy transformation. This assisted in establishing whether there was any difference between the performance of the students from both control and experimental groups. Table 1 presents the results of the mean scores of the students from the two groups in the pretest.

\section{Table 1}

Mean Scores of Students' Performance in the Pretest

\begin{tabular}{lllll}
\hline Group & $n$ & $M$ & $S D$ & Max score \\
\hline Control & 30 & 3.2 & 1.3 & 6 \\
Experimental & 23 & 2.9 & 1.3 & 6 \\
\hline
\end{tabular}

The results from Table 1 show that two-thirds of the students from the control group with a mean $3.2(\mathrm{SD}=$ 1.3, Max score = 6) were found between a scoring range of 1.9 and 4.5. However, two-thirds of the students from the experimental group were found between a scoring range of 1.6 and 4.2. The findings from Table 1 show that students from both control and experimental groups had difficulties in energy transformation. This is because the mean scores were very low. The mean scores from Table 1 however, show that there was a difference between the performance of the students from the control and experimental groups at the pre-intervention stage of the study. The Mann-Whitney U test analysis was used to establish whether the difference in the mean scores was statistically significant. The results of the Mann-Whitney U test analysis of the students' pretest scores are presented in Table 2.

\section{Table 2}

Results of the Mann-Whitney U test of Students' Performance in the Pretest

\begin{tabular}{llccc}
\hline Group & $n$ & Mean rank & $Z$ & $p$-value \\
\hline Control & 30 & 28.7 & -0.979 & $0.327^{*}$ \\
\hline Experimental & 23 & 24.8 & & \\
\hline
\end{tabular}

Note. * Not significant $p>0.05$

From Table 2, the results show that there was no statistical difference between the mean score of the students from the control group and the mean score of the students from the experimental group. This is because the mean rank (Mean rank $=28.7$, Mann-Whitney $\mathrm{U}=295.0, \mathrm{Z}=-0.979, p=.327$ ) of the students from the 
control group was not statistically significantly different from the mean rank, 24.8 of the students from the experimental group in the pretest on energy transformation. The findings from Table 2 show that the entry point of the students from both groups were the same.

The research question further sought to find out students' performance in energy transformation after the intervention and whether the AM has helped to improve the students' performance in energy transformation. The percentages of students who scored some groups of mark from the control and the experimental groups are presented in a graphical form as in Figure 2.

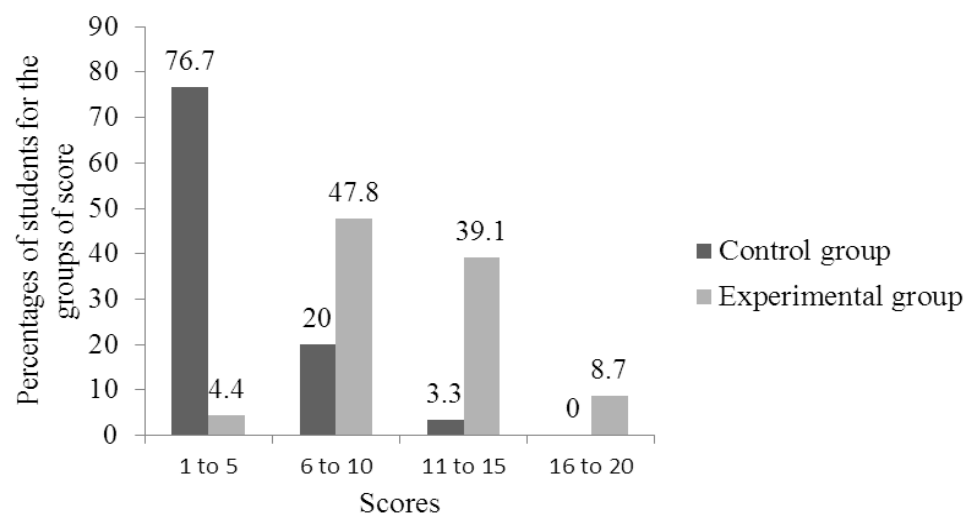

Figure 2. A Bar Graph of the Percentages of Students' Scores in the Posttest

From Figure 2, it could be seen that $76.7 \%$ of the students from the control group scored marks ranging from 1 to 5 while only $4.4 \%$ of the students from the experimental group scored marks ranging from 1 to 5 ; and $20.0 \%$ of the students from the control group and $47.8 \%$ of the students from the experimental group respectively scored marks ranging from 6 to 10. It could also been seen from the results in Figure 2 that $3.3 \%$ of the students from the control group and $39.1 \%$ of the students from the experimental group scored marks between 11 and 15; and only $8.7 \%$ of the students from the experimental group with no one from the control group scored marks between 16 and 20.

The findings from Figure 2 show that majority (90.7\%) of the students from the control group scored marks less than or equal to 10 whereas only $3.3 \%$ of the students from the same group scored marks greater than 10 and up to 15. It can further be deduced from the findings in Figure 2 that $47.8 \%$ of the students from the experimental group scored marks greater than 10. With respect to the percentage of students who scored marks greater than 10, it could be said that the students from the experimental group perform better than the students from the control group.

To further give statistical meaning to the performance of the students in the posttest and define the extent of the effect of the intervention on the performance of the students in the posttest, the results of the students' mean scores in the posttest are presented in Table 3.

\section{Table 3}

Mean Scores of Students' Performance in the Posttest

\begin{tabular}{llrrc}
\hline Group & $n$ & \multicolumn{1}{c}{$M$} & $S D$ & Max score \\
\hline Control & 30 & 4.1 & 2.7 & 11 \\
Experimental & 23 & 11.3 & 3.4 & 18 \\
\hline
\end{tabular}

From Table 3, the results show that two-thirds of the students from the control group with a low mean $(\mathrm{M}=$ 4.1, $\mathrm{SD}=2.7$, Max score = 11) scored marks between the range of 1.4 to 6.8 and two-thirds of the students from the experimental group with a high mean $(\mathrm{M}=11.3, \mathrm{SD}=3.4$, Max score $=18)$ scored marks ranging between 
Adu-Gyamfi, K.

7.9 and 14.7. The findings from Table 3 show that the mean score of the students from the experimental group is higher compared to the mean score of the students from the control group. The Mann-Whitney U test analysis was once again used to test whether the difference between the means of students from the two groups was statistically significant. Table 4 presents the results of the Mann-Whitney U test on the students' posttest scores.

\section{Table 4}

Results of the Mann-Whitney U Test of Students' Performance in the Posttest

\begin{tabular}{llccc}
\hline Group & $n$ & Mean rank & $Z$ & $p$-value \\
\hline Control & 30 & 16.9 & -5.495 & 0.000 \\
Experimental & 23 & 40.2 & & \\
\hline Note. Significant $p<0.05$ & & & &
\end{tabular}

From Table 4, it could be observed that there was statistical significant difference between the performance of the students from the control and the experimental groups in the post-intervention test. This is because the mean rank (mean rank $=16.9$, Mann-Whitney $\mathrm{U}=41.0, \mathrm{Z}=-5.495, p=.000$ ) of the students from the control group was lower than the mean rank, 40.2 of the students from the experimental group in the posttest on energy transformation.

\section{Discussion}

The findings from the pretest show that the students involved in the study show low performance and therefore have difficulty in energy transformation. However, the findings from posttest show that the students who were taught energy transformation through the use of AM perform creditably well than students who were taught energy transformation through the traditional lecture method. The students from the experimental group performing well in the posttest after the intervention as compared to the performance of the students from the control group confirms the studies of Ergul et al. (2011); Khan and Iqbal (2011), which show that there was statistical significant difference between students who were taught some process skills respectively in Physics and Biology through the use of an activity-based lesson and those students who were taught with the traditional lecture method. These previous studies as well as the current study show that the students from the experimental groups outperformed their counterparts from the control group. Hence, the use of AM helps to improve the performance of students in energy transformation as it was in the case of McBride et al. (2004), where an activity-based lesson helped students to improve on their performance in Physics. This current study has shown that when students are taught scientific concepts using locally available materials in the environment, which students are familiar with, to that of the conventional science materials and equipment, their performance could improve. This shows that students' familiarity with the environment is still an important factor to consider in Basic School science lessons in the 21st Century.

In the AM adapted for the study, the students actively constructed their own meaning of energy transformation by interacting with materials. This implies that students should appreciate the fact that they need to construct their own meaning of scientific material whenever it is presented to them (Gallagher, 2000). Further in the AM instruction, students were grouped, made to interact with materials, and communicate among group members. This enhanced the students' understanding in energy transformation and hence, their improved performance in energy transformation. This could be attributed to the fact that social constructivists share the view that meaning is co-constructed before it is internalized; and this is achieved through students' communication among themselves as they actively interact with materials (Woolfolk, 2007). Basic School science teachers are therefore encouraged to adapt activity-based lessons (AM) in teaching science where students can communicate among themselves on scientific material; and learn from each other. 


\section{Conclusion}

The study has shown that the use of the AM has helped the students involved in the study to perform well in energy transformation and therefore the AM can be used to help JHS students improve on their performance in scientific concepts and principles such as energy transformation as suggested by MOEYS (2006). It is therefore recommended that science teachers at the JHS level should incorporate the AM, where students are allowed to interact with teaching and learning materials, into the teaching of Integrated Science at the JHS level, and that the Ghana Education Service should collaborate with the expects in the use of AM to run workshops and seminars to enhance the skills and competencies of the science teachers at the JHS level in the use of AM.

\section{References}

American Association for the Advancement of Science. (1990). Effective learning and teaching: Principles of learning; teaching Science, Mathematics, and Technology. Retrieved December 01, 2011, from www.project2061.org/publications/sfaa/online/chap13.htm

Clark, J. C. (2003). Practical activities: What science teaching can learn from primary classrooms? A paper presented at the Annual Conference of NZARE/AARE, Auckland.

Cohen, L., Manion, L., \& Morrison, K. (2005). Research methods in education (5th ed.). London: Taylor \& Francise-Library.

Ergul, R., Simsekli, Y., Calis, S., Ozdilek, Z., Gocmencelebi, S., \& Sanli, M. (2011). The effects of inquiry-based science teaching on elementary school students' science process skills and science attitudes. Bulgaarian Journal of Science and Education Policy, 5, 48-68.

Gallagher, J. J. (2000). Teaching for understanding and application of science knowledge. School Science and Mathematics Journal, 100(6), 310-316. http://dx.doi.org/10.1111/j.1949-8594.2000.tb17325.x

Herrman-Abell, C. F., \& Deboer, G. E. (2011). Investigating students' understanding of energy transformation, energy transfer, and conservation of energy using standards-based assessment items. A paper presented at the 2011 NARST Annual Conference, Orlando, FL.

Khan, M., \& Iqbal, M. Z. (2011). Effect of inquiry lab teaching method on the development of scientific skills through the teaching of Biology in Pakistan. Language in India: Strength for Today and Bright Hope for Tomorrow, 11(ISSN 1939-2940), 169-178.

McBride, J. W., Bhatti, M. I., Hannan, M. A., \& Feinberg, M. (2004). Using an inquiry approach to teach science to secondary school science teachers. Physics Education, 39(5), 1-6. http://dx.doi.org/10.1088/0031-9120/39/5/007

Ministry of Education, Youth, and Sports. (2006). Methods of teaching integrated science [Course: PFC 214]. Accra: Teacher Education Division.

Pallant, J. (2005). SPSS survival manual: A step by step guide to data analysis using SPSS for windows (ver. 12). Sydney: Ligare.

Pratt, H., \& Hackett, J. (1998). Teaching science: The inquiry approach. Principal, 78(2), 2-20.

Woolfolk, A. (2007). Educational psychology (10th ed.). New York: Pearson Education, Inc. 
Adu-Gyamfi, K. 